\title{
APRESENTAÇÃO DA TRADUÇÃO BRASILEIRA DA FILOSOFIA DO DIREITO DE G.W. F. HEGEL
} PRESENTATION OF the BRAZILIAN TRANSLATION
OF THE PHILOSOPHY OF RIGHT BY G. W. F. HEGEL

Paulo Meneses Agemir Bavaresco Alfredo de Oliveira Moraes Danilo Vaz-Curado R.M. Costa Greice Ane Barbieri Paulo Roberto Konzen

Dados da tradução brasileira de HEGEL, Georg Wilhelm Friedrich. Linhas Fundamentais da Filosofia do Direito ou Direito Natural e Ciência do Estado em Compêndio. Tradução, notas, glossário e bibliografia de Paulo Meneses et alli. Apresentações de Denis Lerrer Rosenfield e de Paulo Roberto Konzen. São Paulo: Loyola; São Leopoldo: UNISINOS, 2010.

\section{A importância da Filosofia do Direito em específico no pensamento de Hegel}

Para compreender a importância de tal obra em específico no pensamento do autor convém conhecer o contexto histórico em que G.W. F. Hegel redigiu a Filosofia do Direito e o lugar que tal texto ocupa no seu sistema filosófico. Sobre isso, é preciso enumerar alguns aspectos cronológicos da vida e da obra hegeliana. Inicialmente, a Filosofia do Direito é uma obra publicada em 1820/1821; na época, Hegel, com 50 anos de idade, já era professor catedrático na Universidade de Berlim, com extensa experiência pedagógica em Filosofia e tendo publicado a Fenomenologia do Espírito (1807), a Ciência da Lógica (1812-1816) e a Enciclopédia das Ciências Filosóficas (1817), entre outros.

Além disso, tal obra sistemática é fruto de fases distintas de elaboração. Hegel, por exemplo, expõe uma versão da sua Filosofia do Espírito Objetivo, em 1808, nos Escritos de Nuremberg, na chamada

\begin{tabular}{|l|l|l|l|l|l|}
\hline Veritas & Porto Alegre & v. 55 & n. 3 & set./dez. 2010 & p. 251-258 \\
\hline
\end{tabular}


Propedêutica Filosófica. Em 1817, na $1^{\text {a }}$ edição da Enciclopédia das Ciências Filosóficas, ele dedicou à exposição e à análise de tal parte da sua Filosofia os §§ 401-453; depois, em 1827 e 1830, na $2^{\mathrm{a}}$ e na $3^{\mathrm{a}}$ edições da Enciclopédia, ela ocupa os §§ 483-552.

Porém, na Filosofia do Direito, de 1820/1821, o total de parágrafos é mais amplo, por ser a sua obra específica dedicada ao desenvolvimento de tais conceitos. O conteúdo de tal obra, que expõe as mesmas divisões da Enciclopédia, envolve muito mais elementos, pois sua exposição abarca um desenvolvimento maior do conteúdo. Afinal, o texto envolve 53 parágrafos na $1^{\mathrm{a}}$ edição e 70 na $2^{\mathrm{a}}$ e $3^{\mathrm{a}}$ edições da Enciclopédia, enquanto que o texto da Filosofia do Direito envolve 360 parágrafos.

Assim, podemos ver a grande diferença numérica de parágrafos dedicados ao desenvolvimento do mesmo conteúdo, confirmando a importância da Filosofia do Direito, dado que reúne um número muito mais vasto e detalhado de elementos. Contudo, demonstra como o texto da Filosofia do Direito não pode ser lido isoladamente, dado que constitui apenas uma parte (isto é, o Espírito Objetivo) da terceira parte (a Filosofia do Espírito) do Sistema Filosófico de Hegel. Ora, Hegel afirma tal aspecto no Prefácio, de 1820, da sua Filosofia do Direito: "Este manual é uma exposição ulterior, em particular mais sistemática, dos mesmos conceitos fundamentais, que sobre essa parte da filosofia já estão contidos na Enciclopédia das Ciências Filosóficas (Heidelberg, 1817)".

Além disso, cabe ressaltar que os textos da $2^{\mathrm{a}}$ e da $3^{\mathrm{a}}$ edições da Enciclopédia (1827 e 1830), apesar de serem cronologicamente posteriores ao da Filosofia do Direito e terem sido remanejados e enriquecidos por Hegel, em relação ao texto da $1^{a}$ edição, não expõem uma reelaboração dos conceitos apresentados na Filosofia do Direito. Mas, antes, procuram reafirmar a atualidade de sua exposição, esclarecendo alguns aspectos e, inclusive, justificando o caráter mais sumário da sua exposição sobre a Eticidade, ao registrar no § 487: "Como já desenvolvi essa parte da Filosofia em minhas 'Linhas Fundamentais [da Filosofia] do Direito' (Berlim, 1821), posso expressar-me aqui mais brevemente do que a propósito das outras partes".

Com isso, em síntese, Hegel reafirma toda a importância e a necessidade de se analisar a sua Filosofia do Espírito Objetivo a partir do texto da Filosofia do Direito. E, em função da relevância da Filosofia do Direito no Sistema Hegeliano, é necessário reconhecer o lugar e o papel privilegiado de tal escrito sistemático, de 1820/1821, na Filosofia Política de Hegel. Por fim, a Filosofia do Direito é especial por ter sido publicada pelo próprio Hegel, o qual a considerou como o texto mais amplo e sistemático que versa sobre a sua Filosofia do Espírito Objetivo, e ainda 
por ser o compêndio de referência de suas lições sobre tal tema ${ }^{1}$, inclusive tendo sido objeto de anotações pessoais.

\section{A importância da Filosofia do Direito em relação à Filosofia e ao Direito}

A Filosofia do Direito de Hegel, sob o ponto de vista lógico, quer ser um grande suprassumir do pensamento jurídico, moral e ético do Ocidente, o lugar e o momento em que desembocou esse longo percurso, o qual deve ser entendido não sob a forma de uma mera coletânea e soma de partes, mas de uma sinopse que, ao adentrar a realidade em busca de suas figuras constitutivas, reúne os distintos pensamentos que procuraram, nas respectivas épocas, dar razão ao espírito de seu tempo. Além disso, a Filosofia do Direito de Hegel é uma obra cuja importância aumenta ainda mais se enfocada a partir de um movimento de configuração, através do qual a ideia de liberdade chegou a pensar-se como produto de um processo histórico. Ela expõe o pensar de uma "lógica do político", que é, como toda reflexão de Hegel, prospectiva e voltada para o futuro. Trata-se do processo de formação da ideia de liberdade ou, mais concretamente, do modo através do qual essa ideia se dá progressivamente a conhecer, despertando os indivíduos inclusive para efetivar a própria liberdade.

Em suma, a Filosofia do Direito deve ser lida e estudada, pois é a obra em que Hegel desenvolve de forma mais ampla e sistemática a sua Filosofia Política. Nela Hegel descreve o desenvolvimento da trajetória da instituição da liberdade na Filosofia Política Moderna através dos conceitos de pessoa, sujeito, membro e cidadão, articulando na plasticidade das figurações institucionais a dialética do espírito do povo, do espírito do tempo e do espírito do mundo. Assim, a ideia de liberdade inclui esse movimento especulativo capaz de afirmar as grandes conquistas da humanidade, carregadas historicamente pelo espírito de um povo, na novidade de cada figuração histórica, apresentando especulativamente as inovações conceituais do espírito de seu tempo. A atualidade de um pensador como Hegel reconhece-se pela força de sua Filosofia deixar-se dizer sempre de novo através de novas leituras e interpretações, capazes

1 Hegel, como consta, lecionou sete vezes o seu curso de Filosofia do Direito: a saber, na Universidade de Heidelberg no semestre de inverno de 1817-18 e, depois, na Universidade de Berlim também nos semestres de inverno de 1818-19, 1819-20, 1821 22, 1822-23, 1824-25 e 1831-32. Mas, nos quatro últimos semestres, Hegel pôde lecionar tendo o manual ou o compêndio da Filosofia do Direito, publicado em 1820/21, como referencial. Ora, nos demais semestres, entre 1825 e 1831, tal curso de Filosofia do Direito não foi interrompido, mas foi ministrado pelo aluno Eduard Gans, o qual também usou como texto de referência a Filosofia do Direito de Hegel. 
de dar conta dos novos cenários e dos contextos sociopolíticos de cada época. Enfim, os leitores poderão ter em mãos uma obra que permite fazer um diagnóstico, ao mesmo tempo, retrospectivo, pois descreve as contradições da sociedade, e prospectivo, pois mostra o sentido da legalidade, da moralidade e da eticidade como efetivação da ideia de liberdade.

\section{O grande diferencial da nova tradução da Filosofia do Direito}

A equipe de tradutores empenhou-se para disponibilizar essa obra clássica ao público especializado e plural, considerando a necessidade de um texto em português que fosse completo e coerente à terminologia hegeliana. Ora, temos a satisfação de oferecer uma tradução que atende, ao mesmo tempo, aos requisitos científicos, ao rigor da escolha terminológica, à fidelidade ao texto original e à expressão da língua portuguesa. Ou seja, o grande diferencial da nova tradução da Filosofia do Direito em português é ser completa e coerente à terminologia de Hegel, efetuada a partir do texto original em alemão, e realizada por estudiosos hegelianos, com reconhecido histórico acadêmico, sobretudo do Prof. Dr. Paulo Meneses e do Prof. Dr. Agemir Bavaresco, tradutores de outras obras de Hegel. Além disso, inserimos o "Glossário Alemão - Português", a fim de orientar o leitor e mostrar os critérios filológicos adotados, e a "Bibliografia de G. W. F. Hegel - Filosofia do Direito", a fim de evidenciar a obra de referência e os demais textos consultados.

As traduções existentes ou eram incompletas ou não coerentes com a terminologia hegeliana, sendo alvo de constantes críticas ou provocando interpretações equivocadas da filosofia de Hegel. Esperamos que as futuras leituras do pensamento de Hegel, fundamentadas numa análise filológica, histórica e hermenêutica da obra hegeliana, possam apreender devidamente os conceitos hegelianos e a riqueza de suas reflexões. Enfim, assim poderemos analisar as interpretações existentes acerca da filosofia hegeliana, pois há uma disputa entre o que ele, a princípio, disse e aquilo que dizem que Hegel disse e/ou do que poderia ou deveria ter dito.

Além disso, cabe destacar que, na presente edição, traduzimos o texto que Hegel escreveu, isto é, os caputs e as respectivas anotações e notas de rodapé que compõem os parágrafos publicados pelo autor. Assim, toma-se contato com o que o autor realmente publicou, procurando extrair o espírito de sua letra, afinal os adendos são registros e, de certa forma, podem ser meras interpretações dos alunos das lições ministradas por Hegel. Muitas análises da Filosofia do Direito baseiam-se apenas em comentários feitos a partir dos adendos e não da obra publicada por Hegel. 


\section{Os detalhes que devem ser ressaltados da nova tradução da Filosofia do Direito}

Dada a importância desta obra clássica para o avanço da pesquisa acadêmica e a necessidade de disponibilizar este texto aos interessados nas diversas áreas, sobretudo da Filosofia e do Direito, oferecemos, agora, uma tradução brasileira completa e coerente à terminologia hegeliana. Afinal, a tradução foi realizada a partir do texto original alemão da Filosofia do Direito, publicado em 1820/1821, e efetuada por estudiosos hegelianos, com reconhecido histórico acadêmico, sobretudo do Prof. Dr. Paulo Meneses, tradutor brasileiro de outras obras de Hegel, a saber, da Fenomenologia do Espírito (Vozes, 1992/2002) e da Enciclopédia das Ciências Filosóficas (Loyola, 1995-7), e do Prof. Dr. Agemir Bavaresco, tradutor de Sobre as Maneiras Científicas de Tratar o Direito Natural (Loyola, 2007). A obra apresenta, ainda, um "Glossário Alemão - Português" e uma "Bibliografia de G. W. F. Hegel - Filosofia do Direito". Além disso, a publicação contém a valiosa apresentação do Denis Lerrer Rosenfield, notável hegeliano, com reconhecidas publicações sobre Hegel.

\section{O trabalho específico da tradução}

Segue breve relato da motivação comum dos tradutores, os contatos e os encaminhamentos dos trabalhos da tradução. E, depois, consta a área de pesquisa e a formação de cada tradutor.

\section{I - A motivação dos tradutores}

Nós tínhamos a cada evento filosófico ou hegeliano uma pergunta inevitável a ser respondida: Já foi publicada a tradução brasileira da Filosofia do Direito de Hegel? E a resposta negativa era sempre motivo de certo mal-estar. Diante desse questionamento permanente surgiu a ideia de realizarmos a tradução dessa obra.

No Congresso da Sociedade Hegel Brasileira que ocorreu em 2009, em Fortaleza, essa ideia ganhou força e assumimos o desafio de traduzir a referida obra para ser lançada na ANPOF 2010. Começamos a superar uma visão de que alguém poderia ter exclusividade na tradução de uma obra, ou ainda, que um texto poderia ter uma única tradução numa mesma língua. Todos nós somos sabedores que a Filosofia do Direito de Hegel tem nas línguas neolatinas e anglo-americanas várias versões, correspondendo a sempre novas recepções dessa obra clássica de Filosofia Política.

Retornando do Congresso, iniciamos os contatos para organizarmos uma equipe de tradutores. Entendíamos que isso deveria ser uma 
obra coletiva, rompendo um paradigma: o trabalho solitário de um único tradutor. Ao contrário, pensamos que um grupo de tradutores poderia oferecer uma tradução mais consistente. Assim, depois de vários contatos e de muitos convites, constituímos o grupo de quatro diferentes Universidades: UNICAP, UFPE, PUCRS e UFRGS e seis pesquisadores hegelianos: Paulo Meneses, Agemir Bavaresco, Alfredo de Oliveira Moraes, Danilo Vaz-Curado R. M. Costa, Greice Ane Barbieri e Paulo Roberto Konzen. Somou-se ao nosso grupo Denis Lerrer Rosenfield, que aceitou fazer a apresentação da obra.

Uma vez constituída a equipe, os trabalhos iniciaram em outubro de 2009 e foram concluídos em abril de 2010. Foram seis meses de trabalho ininterrupto, numa determinação hegeliana permanente, inspirados no aforismo hegeliano: "Nada de grande se fez no mundo sem paixão".

Ao mesmo tempo, articulamos as Editoras para viabilizar a publicação da obra. Aqui, também, conseguimos reunir três instituições e duas editoras: a Editora Loyola e UNISINOS e a Universidade Católica de Pernambuco (UNICAP). Tendo constituído esse grupo editorial, o texto traduzido foi enviado em fins de abril para as Editoras, retornando os originais para serem revisados em fins de julho. Assim, os originais nas suas idas e vindas entre a revisão dos tradutores e os revisores das Editoras ficaram prontos para serem impressos no início de setembro. E eis que o anúncio da obra já impressa viria com a chegada da primavera, em fins de setembro. Para, enfim, no dia 06 de outubro de 2010, ser lançada no quadro do XIV Encontro Nacional da ANPOF, em Águas de Lindóia, São Paulo. Havia transcorrido um ano: outubro de 2009 - outubro de 2010. Ou seja, num verdadeiro tour de force, o grupo de tradutores, juntamente, com revisores e as editoras conseguiram entregar ao público a tradução dessa obra, em tempo relativamente curto. E, agora, dentro dessa travessia do tempo, após 190 anos $^{2}$ de sua publicação pelo autor, podemos realizar o lançamento dessa tradução em português no Brasil.

\section{II - O perfil dos tradutores}

A equipe de tradutores constituiu-se de pesquisadores hegelianos que, ao longo dos anos, desenvolveram suas especializações e pesquisas em Hegel, no sentido de realizar a recepção de seu pensamento e atualizar sua Filosofia. Eis uma breve descrição de sua formação e pesquisa.

2 O frontispício da edição original traz a data de 1821, mas a data de publicação é questionável. A princípio, pode-se dizer que a obra foi concluída em 25 de junho de 1820, data que Hegel registra no Prefácio. A impressão, porém, demorou mais que o habitual por causa da censura vigente. Em todo caso, consta que, em 10 de outubro de 1820, Hegel enviou uma cópia do livro, há pouco publicado, ao ministro prussiano Altenstein (ver Briefe, Bd. II). 
a) Paulo Meneses: Graduado em Filosofia pela Faculdade Pontifícia de Friburgo e Doutor em Filosofia pela Universidade Católica de Pernambuco (UNICAP), onde lecionou no departamento de Filosofia. Coordenou o Núcleo de Estudos da América Latina (NEAL) da UNICAP. De sua autoria, citamos a obra Para Ler a Fenomenologia do Espírito (São Paulo: Loyola, 1985). Suas traduções de Hegel são as seguintes: Fenomenologia do Espírito (Vozes, 1992/2002), a Enciclopédia das Ciências Filosóficas em três volumes: Ciência da Lógica (São Paulo: Loyola, 1995), Filosofia da Natureza (Idem, 1997) e Filosofia do Espírito (Idem, 1995).

b) Agemir Bavaresco: Doutor em Filosofia - Universite de Paris I (Pantheon-Sorbonne) (1997), com o título: La Théorie Hegelienne de l'Opinion Publique. Publicou os seguintes livros sobre Hegel: La Théorie Hégélienne de l'Opinion Publique (Paris/Montréal: L'Harmattan, 1998); Le Mouvement Logique de l'Opinion Publique (Idem, 1999); La Phénoménologie de l'Opinion Publique (Ibidem, 2000); A Teoria Hegeliana da Opinião Pública (Porto Alegre: LP\&M, 2001); A Fenomenologia da Opinião Pública (São Paulo: Loyola, 2003). Além da tradução e apresentação da obra de Hegel: Sobre as Maneiras Científicas de Tratar o Direito Natural (Idem, 2007). Professor do Departamento em Filosofia da PUCRS e Coordenador do PPG/Fil/PUCRS.

C) Alfredo de Oliveira Moraes: Doutor em Filosofia - UFRGS (2001). Tese: A Metafísica do Conceito: Sobre o Problema do Conhecimento de Deus na Enciclopédia das Ciências Filosóficas de Hegel. Livro publicado: A Metafísica do Conceito (Porto Alegre: EDIPUCRS, 2003). Autor de vários artigos e capítulos de livros sobre a filosofia de Hegel. Professor Adjunto do Departamento em Filosofia da UFPE e Coordenador do PPG/Fil/UFPE; docente no Programa de Doutorado Interinstitucional de Filosofia UFPB/UFPE/UFRN. Colaborou na tradução e depois na revisão do volume único, por ocasião dos dez anos da edição brasileira, da Fenomenologia do Espírito de Hegel; além disso, foi um dos fundadores e Presidente da Sociedade Hegel Brasileira (SHB).

d) Danilo Vaz-Curado R. M. Costa: Doutorando em Filosofia pela UFRGS, Bolsista CAPES, tendo como objeto de tese "A Estrutura Lógica do Reconhecimento". Desenvolve pesquisa no (i) Direito, notadamente na relação nem sempre simétrica da recepção pelo Direito Civil dos princípios constitucionais, assim como da relação entre o Direito Civil e o Direito do Trabalho; (ii) na Filosofia, estuda as relações entre Lógica e Filosofia do real, notadamente a relação entre a lógica que vai de Aristóteles à Kant e sua recepção por Hegel. Publicou o livro: Hegel: Liberdade e Razão (Olinda: Livro Rápido, 2004). Publicou artigos sobre Hegel em várias revistas científicas. 
e) Greice Ane Barbieri: Doutoranda em Filosofia pela UFRGS, Bolsista CNPq, tendo como projeto de tese o conceito de família, tal como apresentado na Filosofia do Direito de Hegel. Fez seu mestrado na UFRGS, onde defendeu dissertação que versa sobre "O aspecto positivo da Moralidade na Filosofia do Direito de Hegel". Também é membro-fundador do Núcleo de Estudos Hegelianos (NEHGL), com publicações na Revista de Estudos Hegelianos, Intuitio (PUCRS), Controvérsia (UNISINOS).

f) Paulo Roberto Konzen: Doutorando em Filosofia na UFRGS, Bolsista CNPq. Membro-fundador do NEHGL. Pesquisa atualmente os seguintes temas: Filosofia do Direito, Filosofia Política, História da Filosofia, Ética, sobretudo os conceitos de Estado, de publicidade, de liberdade de imprensa, de opinião pública e de cultura na Filosofia do Direito de Hegel. A dissertação intitula-se "O conceito de Estado e o de liberdade de imprensa na Filosofia do Direito de G.W.F. Hegel" e a tese versa sobre "A relação dos conceitos de publicidade e de liberdade de imprensa na Filosofia do Direito de G.W.F. Hegel". Autor de vários artigos sobre a filosofia hegeliana. 